\title{
Fenestrated brachial vein perforated by the lateral root of median nerve: a case report
}

\author{
Ahmet Songur, Ramazan Uygur, Sezer Akçer, Muhsin Toktaş \\ Department of Anatomy, School of Medicine, Kocatepe University, Afyonkarahisar, Turkey
}

\begin{abstract}
Variations of venous pattern in the arm are common. In this case report, we present a variation of brachial vein (BV) and lateral root of median nerve (LRMN). During routine educational dissections of axillary region, it was observed that a fenestrated BV was perforated by LRMN in the right arm of an old male cadaver. LRMN was not exposed to compression as it passed through the fenestration. It then joined the medial root of the median nerve to form the median nerve. The fenestrated segment of BV was narrow. However, BV coursed normally beyond this segment. There was no other anatomical variation in BV and LRMN both prior to the fenestrated segment and beyond it. Veins of the upper limb are commonly used for total parenteral nutrition, therapeutic invasive procedures, blood samples, blood transfusion, and catheterization and occasionally for grafting procedures. A large number of invasive procedures, both diagnostic and therapeutic are carried out using veins of the upper limb, particularly in and distal to the axillary region. Classic and variational anatomy of the upper limb is important with regards to surgical exposure of vessels in this region. Perforation of BV by the LRMN is a rare variation. Consequently, we think that it is important for the surgeons to keep this variation in mind in order to avoid possible complications such as nerve injury.
\end{abstract}

Key words: brachial vein; fenestration; median nerve; variation; dissection

Anatomy 2009; 3: 65-68, () 2009 TSACA

\section{Introduction}

The ulnar and radial veins of the forearm unite to form brachial veins near the elbow joint. Anterior and posterior interosseal veins join these veins near the elbow joint. The brachial veins flank the brachial artery, as comitant veins with tributaries similar to the arterial branches. They then join the axillary vein near the lower margin of subscapularis muscle. The medial branch, however, often joins the basilic vein before it becomes the axillary vein. ${ }^{1,2}$

Lateral and medial roots, which are the terminal branches of lateral and medial cords of brachial plexus, unite to form the median nerve anterior to the axillary artery. The median nerve runs downwards with brachial artery and ulnar nerve in the groove medial to the biceps brachii muscle. ${ }^{3}$
Variations of the venous pattern in the arm are common. ${ }^{4}$ Here we describe a rare variation of fenestrated brachial vein (BV) and its relations to the lateral root of median nerve (LRMN) which perforates it and discuss the morphological importance and clinical implications.

\section{Case Report}

During routine educational dissections of axillary region, it was observed that a fenestrated $\mathrm{BV}$ was perforated by LRMN in the right arm of an old male cadaver (Figure 1). LRMN was not exposed to compression as it passed through the fenestration. It then joined the medial root of median nerve to form the median nerve. The fenestrated segment of BV was narrow. However, BV 


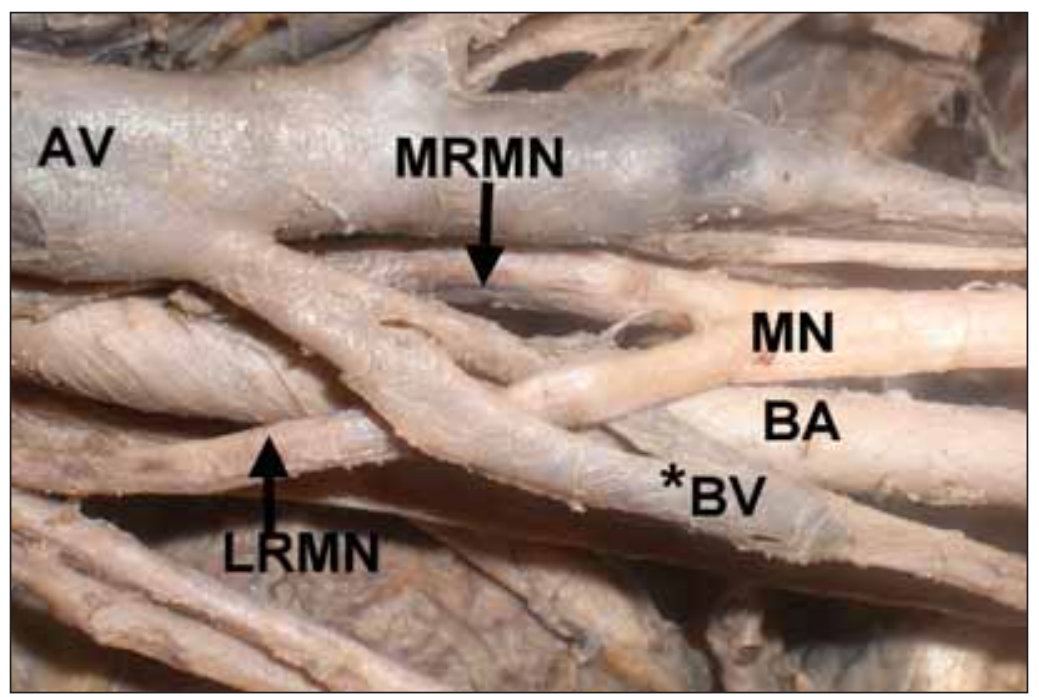

Figure 1. A variation of fenestrated brachial vein in the right arm of an old male cadaver. AV: axillary vein; BA: brachial artery; *BV: brachial vein; LRMN: lateral root of median nerve; MRMN: median root of median nerve; MN: median nerve.

coursed normally beyond this segment. There was no other anatomical variation in BV and LRMN both prior to the fenestrated segment and beyond it.

\section{Discussion}

In the embryologic term, a dense capillary plexus forms initially in the limb bud mesenchyme. As a result of different hemodynamic influences, some anastomoses develop between superficial and deep vessels, whereas others do not develop or regress. In this way, the superficial and deep blood vessels arise. The superficial capillary plexus persists for the development of superficial veins of the upper limb. The axonal growth cones for the cutaneous nerves also travel through the undifferentiated mesenchyme intermingled with the developing vascular channels. Therefore, there is the possibility that an axonal growth cone will become entrapped within the venous plexus to give rise to the variant morphology in the present case. ${ }^{4}$

Veins of the upper limb are commonly used as an intravenous route for total parenteral nutrition, fluid and electrolyte infusion, therapeutic invasive procedures, blood samples, blood transfusion, catheterization and occasionally for grafting procedures. A large number of invasive procedures, both diagnostic and therapeutic, are carried out using veins of the upper limb, particularly in and distal to the axillary region.
The development of noninvasive imaging techniques such as CT, sonography, and MRI increased reporting of this entity. ${ }^{6}$ Accordingly, fenestrations of various vessels are observed in many studies. ${ }^{7,8}$ However we did not find fenestration of $\mathrm{BV}$ in literature.

According to personal experience of Prades et al. the clinical incidence of the fenestration anomaly is approximately $0.4 \%$ of unilateral neck dissections. They reported three intra-operative cases in which the lateral branch of the accessory nerve (XI) always passed medially to the anterior vein and laterally to the posterior vein, between the venous duplication. ${ }^{9}$ In a study performed by Talbot on 30 cadavers, it was found that in one specimen there was an accessory phrenic nerve passing through the subclavian vein and dividing it into two channels. ${ }^{10}$ In a series of routine dissections of 400 embalmed human cadavers, Roy et al. observed an axillary vein variation in the right upper limb of a 55-year-old male in whom no variations were observed in the left axillary vein. The medial cutaneous nerve of the forearm penetrated the axillary vein, thereby creating two narrow venous channels at the site of passage. ${ }^{4}$

Upper extremity venous system mapping is important in explaining the etiology of malfunctioning arteriovenous fistulas (AVF), in planning probable interventional radiologic and surgical procedures, such as creat- 
ing new fistulas or placing new catheters. Venous imaging is required to diagnose and evaluate the extension of thrombosis. ${ }^{11}$ Hernan et al. used the BV as an autogenous AVF in the absence of adequate superficial veins in order to create an AVF in two patients with end-stage renal disease. ${ }^{12}$ Patency of the vein, local infection or inflammation, anatomic variations and previous history of surgery, trauma, radiation therapy or burns are important factors for choosing the vein to place catheters. ${ }^{13}$ Central venous catheterization is used for patients who will undergo major operations and in intensive care units for central venous pressure (CVP) monitoring, administration of fluids and medications, parenteral nutrition, aspiration of air emboli, transcutaneous pacing procedure and as venous route in patients with inadequate peripheral veins. ${ }^{14}$ Central venous catheters can be placed via either central (internal jugular vein/subclavian) or peripheric intervention. Using catheters extending to superior vena cava after peripheral intervention is less invasive than centrally placed catheters. When placing central catheter via $\mathrm{BV}$, it is advisable to abduct the arm and turn the head to the opposite direction in order to prevent the catheter from entering jugular vein. ${ }^{15}$ Familiarity with the variations of BV reduces the inadvertent effects that may occur during catheterization procedure. The division of the BV into two narrow venous channels to accommodate the passage of LRMN may increase the incidence of thrombi and emboli in cases of prolonged hyperabduction, trauma and laceration, including surgical and invasive procedures such as central venous catheterization.

Tanju et al. conducted a study in order to investigate the diagnostic value of direct contrast-enhanced 3D MR venography in mapping the upper extremity venous system and planning invasive radiological and surgical procedures. They encountered venous pathology in 16 of the 19 cases (84\%). Furthermore they observed two cases of duplication of cephalic vein and one case of internal jugular vein fenestration, being totally three $(15 \%)$ cases of anatomic venous variations. ${ }^{11}$ George et al. reported a case of an abnormal arterial trunk which branched off from axillary artery. This abnormal trunk was sandwiched between the two roots of median nerve at its origin. Furthermore, unlike our case, the medial root of the median nerve passed deep to the main continuation of the axillary artery, where it might get compressed leading to nerve compression symptoms. ${ }^{16}$ But we did not observe LRMN compression in our case.

While upper extremity vascular injury is less frequently seen than lower extremity vascular injury, it comprises more than one-third of all peripheral vascular injuries. Upper extremity vascular injury constitutes $30 \%$ of vascular injuries. Since these injuries are important causes of mortality and morbidity and may result in loss of function of the extremity or loss of extremity, early diagnose and treatment is important. Vascular injuries treated late and inadequately may lead to severe complications. ${ }^{17}$ Therefore, knowing vascular variations is of vital importance. BV presented in our case report is one of the most frequently injured veins.

In a study on 137 patients with vascular injuries, Tatar et al. found that the vascular injuries were most commonly seen in brachial artery, axillary artery, radial artery and ulnar artery. They determined only arterial injury in 60 patients, both arterial and venous injury in 77 patients. Venous injuries most frequently occurred in comitant veins, namely BV, axillary vein, radial vein. There were median nerve injury in 7 patients, axillary nerve injury in 11 patients and concurrent tendon injury in 23 patients. ${ }^{17}$

The venous anomaly described in our case has a number of implications for invasive procedures involving this region, trauma surgery and radiological imaging techniques. Surgeons and radiologists should be aware of these anomalies so as to reduce complications. In order to have a good surgical exposure of the upper extremity vessel, it is important to know classic and variational anatomy of the upper limb. Perforation of BV by the LRMN is a rare variation. Consequently, we think that it is important for the surgeons to keep this variation in mind in order to avoid possible complications such as nerve injury. 


\section{References}

1. Arıncı E, Elhan A. Anatomi. Vol 2. 4th ed. Ankara: Güneş Kitabevi; 2006.

2. Drake RK, Vogl W, Mitchell AWM. Gray's Anatomy. 39th ed. Edinburgh: Churchill Livingstone; 2005.

3. Moore KL, Dalley AF. Clinically Oriented Anatomy. 4rd ed. Baltimore: Lippincott Williams \& Wilkins; 1999.

4. Roy TS, Sharma S. Axillary vein perforation by the medial cutaneous nerve of the forearm. Clin Anat 2004; 17: 300-2.

5. Andel H, Rab M, Felfernig M, et al. The axillary vein central venous catheter in severely burned patients. Burns 1999; 25: 753-6.

6. Chen SJ, Liu KL, Chen HY, et al. Anomalous brachiocephalic vein: CT, embryology, and clinical implications. AfR Am 7 Roentgenol 2005; 184: 1235-40.

7. Gardiner KJ, Irvine BW, Murray A. Anomalous relationship of the spinal accessory nerve to the internal jugular vein. Clin Anat 2002; 15: $62-3$.

8. Alaani A, Webster K, Pracy JP. Duplication of internal jugular vein and relation to the spinal accessory nerve. Br 7 Oral Maxillofac Surg 2005; 43: 528-31.

9. Prades JM, Timoshenko A, Dumollard JM, Durand M, Merzougui $\mathrm{N}$, Martin C. High duplication of the internal jugular vein: clinical incidence in the adult and surgical consequences, a report of three clinical cases. Surg Radiol Anat 2002; 24: 129-32.
10. Talbot RW. Anatomical pitfall of subclavian venepuncture. Ann $R$ Coll Surg Engl 1978; 60: 317-9.

11. Tanju S, Sancak T, Düşünceli E, Yağmurlu B, Erden I, Sanlidilek U. Direct contrast-enhanced 3D MR venography evaluation of upper extremity deep venous system. Diagn Interv Radiol 2006; 12 : 74-9.

12. Bazan HA, Schanzer H. Transposition of the brachial vein: a new source for autologous arteriovenous fistulas. 7 Vasc Surg 2004; 40: 184-6.

13. Denny DF. Placement and management of long-term central venous access catheters and ports. AfR Am F Roentgenol 1993; 161: 385-93.

14. Ayoğlu H, Altunkaya H, Özer Y, Yapakçı O, Özkoçak I. Yanlış yerleşimli subklavian ven kateterizasyonuna bağlı kulak ağrısı (olgu sunumu). Anestezi Dergisi (Ankara) 2005; 13: 209-11.

15. Karaslan D. Periferik girişli santral venöz kateter malpozisyonu (olgu sunumu). Anestezi Dergisi (Ankara) 2003; 11: 61-4.

16. George BM, Nayak S, Kumar P. Clinically significant neurovascular variations in the axilla and the arm-a case report. Neuroanatomy (Ankara) 2007; 8: 36-8.

17. Tatar H, Öz BS, Şirin G, et al. Üst ekstremite damar yaralanmaları: cerrahi deneyimlerimiz. Turkish Fournal of Vascular Surgery (Ankara) 2006; 15: 11-5.

Correspondence to: Ahmet Songur MD, PhD Department of Anatomy, School of Medicine, Kocatepe University 03100 Afyonkarahisar, Turkey

Phone: +90 2722171753 e-mail: asongur55@hotmail.com Conflict of interest statement: No conflicts declared. 